\title{
Application of Stem Cell Therapy for ACL Graft Regeneration
}

\author{
Canlong Wang, ${ }^{1,2,3}$ Yejun Hu, ${ }^{1,2,3}$ Shichen Zhang, ${ }^{2,4,5}$ Dengfeng Ruan, ${ }^{1,2,3}$ Zizhan Huang, $^{1,2,3}$ \\ Peiwen He, ${ }^{1,2,3}$ Honglu Cai, ${ }^{1,2,3}$ Boon Chin Heng, ${ }^{6}$ Xiao Chen $\mathbb{D}^{2,4,5}$ \\ and Weiliang Shen $\mathbb{D}^{1,2,3,4,5,7}$
}

\author{
${ }^{1}$ Department of Orthopedic Surgery, 2nd Affiliated Hospital, School of Medicine, Zhejiang University, Zhejiang 310009, China \\ ${ }^{2}$ Orthopaedics Research Institute of Zhejiang University, Zhejiang, China \\ ${ }^{3}$ China Orthopaedic Regenerative Medicine (CORMed), Hangzhou, China \\ ${ }^{4}$ Dr. Li Dak Sum and Yip Yio Chin Center for Stem Cell and Regenerative Medicine, Zhejiang University, Zhejiang 310000, China \\ ${ }^{5}$ Department of Sports Medicine, School of Medicine, Zhejiang University, Zhejiang 310000, China \\ ${ }^{6}$ Central Laboratory, Peking University School of Stomatology, Bejing 100081, China \\ ${ }^{7}$ Department of Orthopedics, Huzhou Central Hospital, Affiliated Central Hospital of Huzhou University, Zhejiang University \\ Huzhou Hospital, Huzhou, Zhejiang 313000, China
}

Correspondence should be addressed to Xiao Chen; chenxiao-610@zju.edu.cn and Weiliang Shen; wlshen@zju.edu.cn

Received 10 December 2020; Revised 19 February 2021; Accepted 30 June 2021; Published 2 August 2021

Academic Editor: Gianpaolo Papaccio

Copyright ( 2021 Canlong Wang et al. This is an open access article distributed under the Creative Commons Attribution License, which permits unrestricted use, distribution, and reproduction in any medium, provided the original work is properly cited.

\begin{abstract}
Graft regeneration after anterior cruciate ligament (ACL) reconstruction surgery is a complex three-stage process, which usually takes a long duration and often results in fibrous scar tissue formation that exerts a detrimental impact on the patients' prognosis. Hence, as a regeneration technique, stem cell transplantation has attracted increasing attention. Several different stem cell types have been utilized in animal experiments, and almost all of these have shown good capacity in improving tendon-bone regeneration. Various differentiation inducers have been widely applied together with stem cells to enhance specific lineage differentiation, such as recombinant gene transfection, growth factors, and biomaterials. Among the various different types of stem cells, bone marrow-derived mesenchymal stem cells (BMSCs) have been investigated the most, while ligament stem progenitor cells (LDSCs) have demonstrated the best potential in generating tendon/ligament lineage cells. In the clinic, 4 relevant completed trials have been reported, but only one trial with BMSCs showed improved outcomes, while 5 relevant trials are still in progress. This review describes the process of ACL graft regeneration after implantation and summarizes the current application of stem cells from bench to bedside, as well as discusses future perspectives in this field.
\end{abstract}

\section{Introduction}

Anterior cruciate ligament (ACL) injuries account for more than $50 \%$ of all knee injuries [1], which may cause knee instability, resulting in meniscal damage and osteoarthritis. When tears occur, ACL reconstruction (ACLR) surgery is usually undertaken, which yields the best therapeutic effects and postoperative evaluation scores for patients [2]. There are over 175,000 patients undergoing ACL surgery annually in the US alone [3], but more than $10 \%$ of patients experience reinjuries, muscular atrophy, delay in healing, poor proprioception, and graft failure after reconstruction in long-term follow-ups [4-7]. Hence, the major challenge is how to improve postoperative graft healing.

After transplantation, the graft goes through a complex three-staged healing process involving necrosis, remodeling, and ligamentization, which may take around 2 years [8]. Moreover, fibrous scar tissue is often formed at the interface, instead of a natural insertion $[9,10]$. When a tissue is characterized by poor healing capacity, such as tendon and ligament, regenerative strategies are usually considered. Several common regenerative approaches, such as stem cells, biomaterials, and bioactive molecules, have been investigated and proven to be effective [11-13]. Among these, stem cells are 
extremely appealing, due to their self-renewal capacity, longterm viability, and multilineage differentiation potential [14]. In particular, mesenchymal stem cell (MSC) can differentiate into various terminally differentiated lineages, which can be utilized to engineer mesenchymal-derived tissues, and also promote healing by secreting various immunoregulatory molecules, such as paracrine trophic mediators $[15,16]$. To induce stem cells to differentiate into a specific lineage, various differentiation inducers are usually utilized, such as recombinant gene transfection, growth factors, and biomaterials. Indeed, an increasing number of preclinical research studies have confirmed that inducers could enhance boneto-tendon healing with better biomechanical properties and more mature tissue formation. Several clinical trials have been attempted, but so far, it is still uncertain whether stem cell augmentation could facilitate the healing process.

The purpose of this review is to describe the natural healing process after ACL graft implantation and summarize the current application of stem cells from bench to bedside, as well as discuss future prospects in this field.

\section{Process of ACL Graft Regeneration}

From the posterior part of the inner surface of the lateral femoral condyle, the ACL runs anteriorly, medially, and distally to the tibia [17]. The main component of ACL tissue is constituted of parallel and closely arranged collagen fibers, and fibroblasts are distributed along the long axial among the collagen fibers [18]. There are three characteristic stages of graft healing after ACL reconstruction in both humans and animals [19]: (i) early phase associated with necrosis and hypocellularity, (ii) remodeling phase associated with revascularization and cell activities, and (iii) ligamentization phase associated with restructuring towards the native ACL [20].

During the early stage, necrosis occurs in the graft centra, which leads to a release of various cytokines, such as tumor necrosis factor- (TNF-) $\alpha$, interleukin (IL) $1-\beta$, IL-6, and chemokines, which may trigger growth factor expression $[21,22]$. Some host cells (neutrophils, macrophages, and MSC) migrate to the graft periphery $[11,12,21]$, and towards the inner tendon [11]. Collagen fibrils begin disintegrating [13], and no graft revascularization could be observed [23, 24]. The collagen fibers of tendon display a bimodal distribution, with large collagen fibers constituting the majority. However, during healing, small fibers increase while large ones decrease (Figure 1(a)). Additionally, new surgery with attached graft may skip early necrosis, which retains the native blood supply $[25,26]$.

During the remodeling stage, large amounts of growth factors are released, which stimulates cell migration and proliferation as well as extracellular matrix synthesis and revascularization $[22,27,28]$. The hypercellular region at the perimeter consists of mesenchymal stem cells and fibroblasts [29]. Activated fibroblasts secrete various growth factors, which almost completely cease at the end of the remodeling stage [22]. The large diameter collagen fibrils get depleted [20], while the Sharpey-like fibers form to counteract shear stress and to attach the tendon graft to bone [30] (Figure 1(b)).
During the maturation stage, cellularity and mechanical properties become gradually similar to intact ACL but never reach the original levels $[31,32]$. Progressive mineralization occurs, with subsequent bony ingrowth into the graft surface. Small collagen fibers predominate while large ones could hardly be seen, which differ significantly from normal ACL, with an unclear bimodal distribution (Figures 1(c) and 1(d)). Moreover, during this stage, more osteoarthritic changes and cartilage damage could be observed, with no significant differences in the expression of inflammatory cytokines or biomarkers [33].

Based on the above description, the graft healing process is slow and requires a long duration. The remodeling stage is finished by 9 months at the earliest [20,34], and ligamentization could be observed after 2 years [8]. In the clinic, patients are usually recommended to return to low and moderate intensity exercise after 6 months [35-37], and typically regain about $85 \%$ function eventually [38]. Hence, a safe and effective approach to expedite the healing process is needed to restore the natural biomechanics of tendon, which is required for rapid return to preinjury activity levels.

\section{Stem Cell Therapy for Graft Regeneration}

Stem cells show remarkable ability for self-renewal, longterm viability, and multilinear culture [14], which is an essential element in tissue engineering technology. In different cultures, stem cells could differentiate into nerve cells, hepatocytes, or blood cells. Combined with materials science, it is possible to construct similar tissues and organs to substitute the injured part. It has been widely proven that stem cells are effective in many diseases, such as central nervous system damage, and corneal destruction [39, 40]. Recent scientific literature has demonstrated promising outcomes of stem cell augmentation for ligament reconstruction in animal models [41-43] (Figure 2 and Table 1). However, the application of stem cells in ACLR requires further consideration of cell resource, differentiation induction, and cell fate.

3.1. Selection of Stem Cell Sources. There are several common cell sources in tissue engineering, such as embryonic stem cells (ESCs), induced pluripotent stem cell (iPSC), adipose tissue-derived stem cells (ADSCs), bone marrow-derived mesenchymal stem cells (BMSCs), and tendon/ligament stem/progenitor cells (TDSCs/LDSCs). In particular, MSC is the focus of much interest, as these cells are easily isolated from a variety of adult tissues and cultured in vitro. Cells from different sources have varying propensities to differentiate into various tendon/ligament lineages, and hence, it is imperative to weigh the pros and cons of various different stem cell types (Table 2 ).

3.1.1. BMSC. BMSCs have multipotential capacity to differentiate into osteoblasts, chondrocytes, and adipocytes and hence have been most widely studied for enhancing tendon-bone healing, yielding satisfactory outcomes (Figure 2(d)). Sakaguchi compared the proliferative capacities of different stem cell types and observed that BMSCs were retained even at passage 10 , whereas that of ADSCs was lost at passage 7 [44], thus 


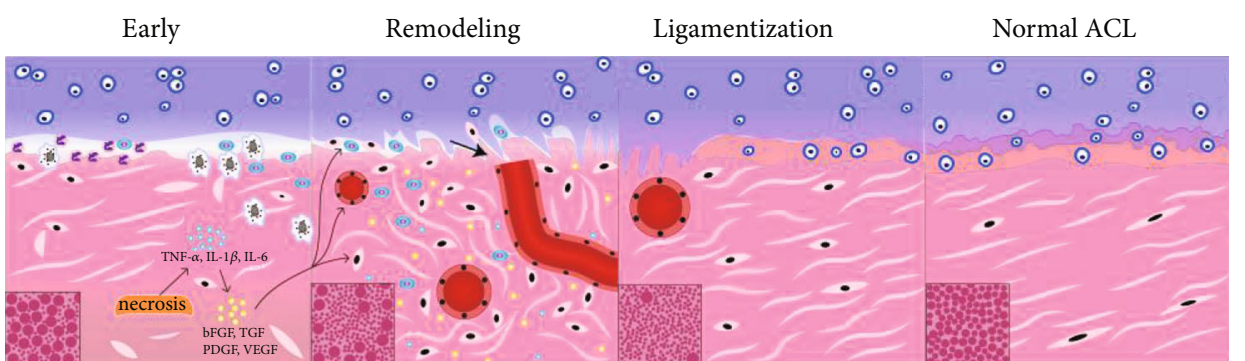

(a)

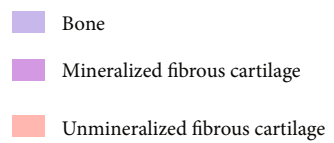

(b)

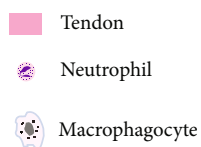

(c)

FIGURE 1: Schematic model for graft regeneration after ACL reconstruction. (a) Early stage characterized by necrosis, fiber disintegration, and cytokine release; neutrophils, macrophagocytes, and mesenchymal stem cells (MSC) can be observed in the interface in order, and then macrophagocytes and MSC migrate into the inner tendon. The collagen fibers displayed a bimodal distribution, with large ones constituting the majority; (b) remodeling stage marked with Sharpey fibers (arrow), cell migration, vascularization, ECM remodeling, various growth factor activities, and disordered organization of collagen fibers (bimodal distribution with small ones constituting the majority); (c) ligamentization stage marked with vascularization gradually disappearing, fibrocartilage formation, and ordered collagen with almost unimodal small fibers; (d) normal ACL, 4-layer direct insertion including ligament, fibrocartilage, mineralized fibrocartilage, and bone in order. The collagen fibers showed unclear bimodal distribution.

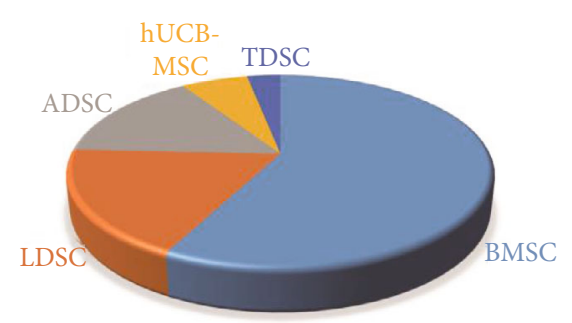

(a)

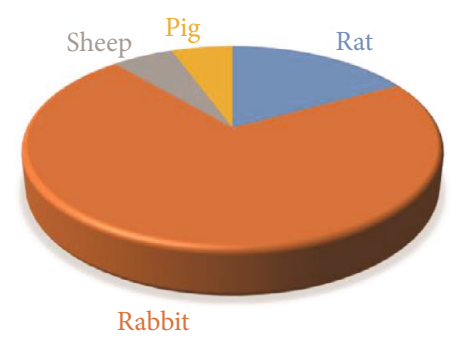

(c)

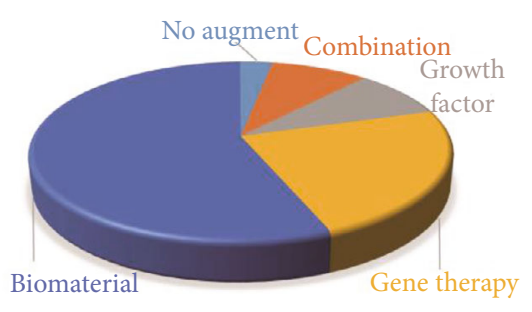

(b)

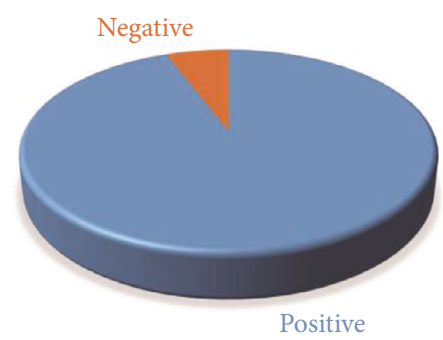

(d)

FIgURE 2: Features of included animal studies. (a) Cell resources; (b) augmentations; (c) animal models; (d) general study outcomes. BMSC: bone marrow-derived mesenchymal stem cells; ADSC: adipose-derived stem cells; hUCB-MSC: human umbilical cord blood-derived mesenchymal stem cells; TDSC: tendon-derived stem cells; LDSC: ligament-derived stem cells.

showing the greater stability of BMSCs. However, these cells are not considered as the optimal choice due to the risk of ectopic ossification and donor injury. The therapeutic effects of BMSCs are thought to result from migration of the cells to inflammatory sites and suppression of inflammation. They are rarely involved in colonizing the healing tissue as part of the tissue repair mechanisms [45].

Lim et al. [46] implanted hamstring tendon autografts into the bone tunnel in rabbits, which was coated with MSCs embedded within a fibrin glue carrier in one limb, and fibrin glue only in the other limb, resulting in cartilage-like insertions rather than scar tissue. A similar study showed that BMSCs could decrease tunnel widening [47].

3.1.2. ADSC. ADSCs have the advantages of abundant and ready availability, as well as capacity for secreting various factors, such as VEGF, hematopoietic factors, and immunoregulatory factors, to promote tissue repair and growth. Over 500 times more stem cells can be obtained from adipose tissue than from an equal tissue volume of bone marrow 
TABLE 1: Recent animal studies on stem cell therapy for ACL graft regeneration.

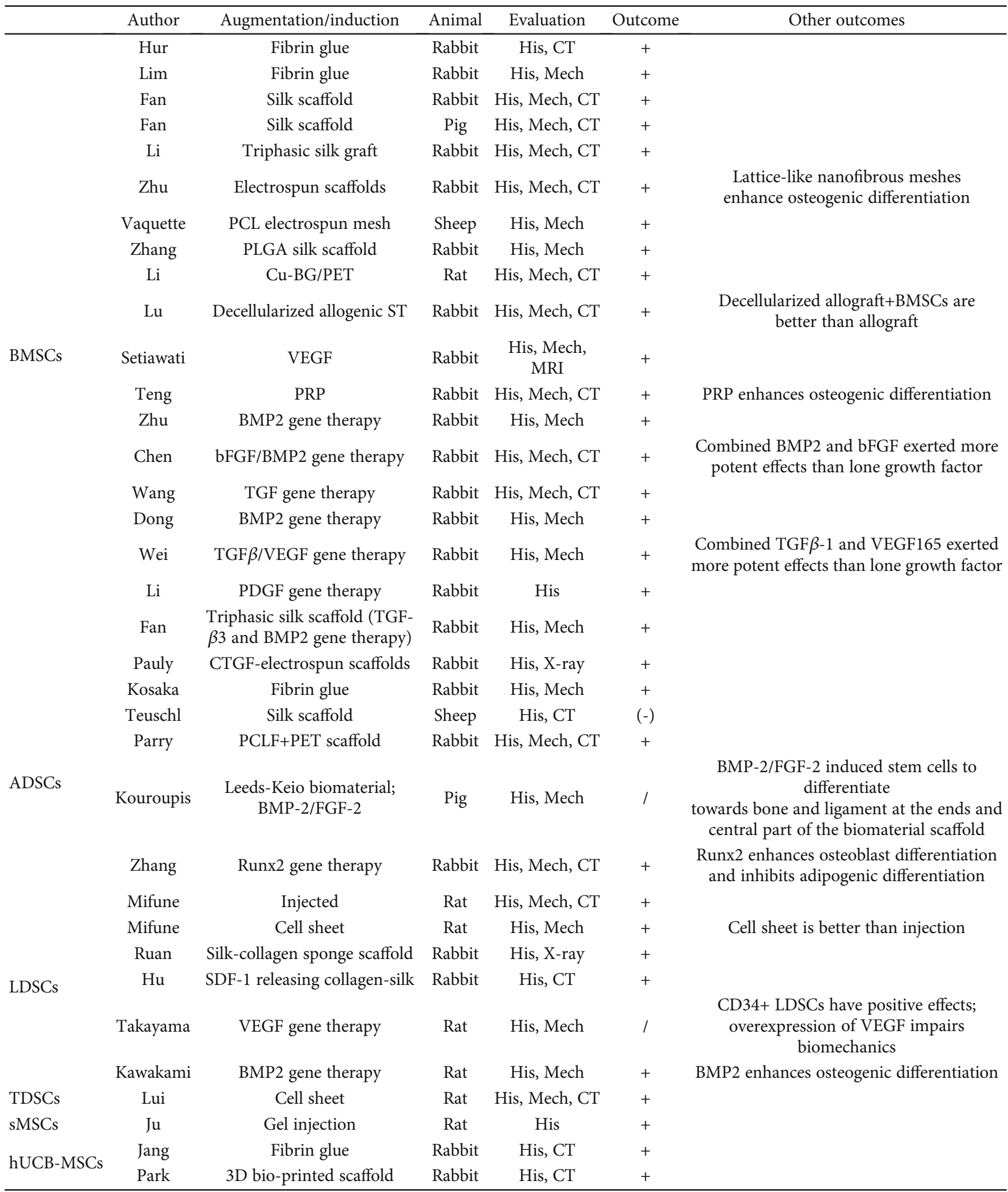

PRP: platelet-rich plasma; His: histology; Mech: mechanics; PCLF+PET: polycaprolactone fumarate scaffolds with polyethylene terephthalate; bFGF: basic fibroblast growth factor; BMP2: bone morphogenetic protein 2; TGF: transforming growth factor; VEGF: vascular endothelial growth factor; PDGF: platelet-derived growth factor; ST: semitendinosis; PCL: polycaprolactone; BMSCs: bone marrow-derived mesenchymal stem cells; ADSCs, adipose-derived stem cells; sMSCs: synovial mesenchymal stem cells; hUCB-MSCs: human umbilical cord blood-derived mesenchymal stem cells; PLGA: lactic-co-glycolic acid; $\mathrm{Cu}-\mathrm{BG} / \mathrm{PET}$ : copper-containing bioactive glass polyethylene terephthalate; Runx2; PCLF+PET: polycaprolactone fumarate+polyethylene terephthalate sutures; SDF: stromal cell-derived factor 1; CTGF: connective tissue growth factor; bFGF: basic fibroblast growth factor. 
TABLE 2: The advantages and disadvantages of commonly utilized stem cell types in ACL graft regeneration.

\begin{tabular}{|c|c|c|c|}
\hline Formulation & Msc content & Advantages & Disadvantages \\
\hline BMSCs & $0.01-0.001 \%[142]$ & $\begin{array}{l}\text { Great proliferation } \\
\text { Low cost } \\
\text { Low immunoreaction } \\
\text { Easy to obtain }\end{array}$ & $\begin{array}{l}\text { Low content } \\
\text { Donor pain and infection } \\
\text { Less homogeneous }\end{array}$ \\
\hline ADSCs & $\sim 1 \%[143]$ & $\begin{array}{c}\text { Abundant resource } \\
\text { More homogeneous } \\
\text { Factor secretion } \\
\text { Less immunogenic than BMSCs }\end{array}$ & $\begin{array}{l}\text { Enzymatic processing } \\
\text { Low ligament differentiative potential [53] }\end{array}$ \\
\hline TDSCs/LDSCs & $3-4 \%[56]$ & $\begin{array}{c}\text { Same derived resource } \\
\text { Better epigenetic regulation [144] } \\
\text { Cell-line maintainment [145] }\end{array}$ & $\begin{array}{l}\text { Slow growth } \\
\text { Low content }\end{array}$ \\
\hline ESC & - & $\begin{array}{l}\text { Indefinite self-renewal [146] } \\
\text { Totipotency }\end{array}$ & $\begin{array}{c}\text { Ethic issue } \\
\text { Tumorigenicity [147] } \\
\text { Immunogenicity [148] }\end{array}$ \\
\hline
\end{tabular}

BMSCs: bone marrow-derived mesenchymal stem cells; ADSCs: adipose tissue-derived stem cells; TDSCs/LDSCs: tendon/ligament stem/progenitor cells; ESCs: embryonic stem cells.

[48], and proteomic analysis of ASC secretome identified a total of 2416 distinct proteins [49]. In addition, ADSCs show lower risk of ectopic ossification, with less immunogenicity than BMSCs [50], causing less damage to the donor site, without the limitations associated with age-related decline of BMSCs. Indeed, ADSCs have demonstrated their suitability for various cell therapy applications including angiogenicity, osteogenicity, immunomodulation, and promotion of tissue remodeling $[51,52]$. However, a study showed that ADSCs cannot continuously upregulate ligament-related markers with growth factors in vitro, as it exhibits a bias towards adipogenic differentiation [53].

It has been reported that ADSCs promote the early healing processes of tendon and bone in rabbits [43]. But Teuschl et al. [54] found that additional ADSCs did not result in any additional benefit for osteointegration, as compared with the silk scaffold group histologically, which showed ambiguous function.

3.1.3. TDSC/LDSC. It has been reported that tissue-specific stem cells may retain a residual "epigenetic memory" of their tissue of origin [55]. When back at their tissue of origin, they could adapt to the environment better, survive longer, and differentiate more easily. TDSCs were first isolated from human hamstring tendon in 2007 [56], while a later study showed the possibility of isolating TDSCs from very small fragments of tendon tissue [57]. These cells proliferated faster, exhibited higher clonogenicity and less immunogenicity, and had more multilineage differentiation potential than BMSCs $[58,59]$. However, the purity of TDSC populations is highly debatable, as it displayed lower adipogenic and osteogenic capacities than ADSCs [60], and lower multilineage differentiation potential than LDSCs [61]. TDSC-related studies are rare but seem promising, exhibiting high tenogenic potential and maintaining high chondroosteogenic gene expression [59].

Originating from the ligament tissue [62], CD90+CD73+ LDSCs tend to differentiate into ligament-committed cells or chondrocytes, as compared with BMSCs $[63,64]$. The appli- cation of LDSCs in vivo has yielded generally positive results, when combined with silk scaffold, cell sheet, and injection $[65,66]$. In particular, CD34+ vascular cells from ligament tissue are considered as another type of adult stem cell and have proven efficacious in tendon-bone regeneration $[66,67]$. As a promising cell source, ACL-derived iPSCs are also under study [68]. The common problem of both is that low cell numbers necessitate expansion, which may influence phenotypic maintenance. Still, TDSCs and LDSCs are considered the most promising cell types for ACL regeneration.

3.1.4. Other Stem Cell Types. hUCB-MSCs: hUCB-MSCs have the advantages of noninvasive isolation method, superior tropism, and high differentiation potential. Transplantation in rabbits enhanced bone-tendon healing effectively, without immune rejection $[69,70]$, while the application of human amniotic mesenchymal stem cells (hAMSCs) is still under research [71].

Synovium-derived MSCs (sMSCs): after injury, a local increase of MSCs was observed, and these MSCs were identified as sMSCs rather than BMSCs [72]. sMSCs can potentially promote collagen fiber production, which resembles Sharpey's fibers at the early stage.

ESC/iPSCs: ESCs could differentiate into any tissue or cell type, but therapeutic applications of these cells have been subjected to serious and prolonged legal/ethical discussion. On the other hand, iPSCs avoided ethical issues associated with ESC and also offered the possibility for autologous regeneration of any tissue. Cord and peripheral blood are attractive sources of reprogrammable cells for generating iPSCs [73, 74]. As a promising cell source, ACL-derived iPSCs are still under research [68]. But current outcomes of therapeutic applications in animal models seem controversial, with transplantation of ESCs into the knee joint of mice resulting in teratoma formation and subsequent destruction of the joint [75]. By contrast, composite grafts with iPSCs in pigs showed similar morphological and biochemical characteristics to normal ACL [76]. 
Exosome: no related research studies have been reported yet. However, the application of exosomes in tendon injury and tendinopathy in animal models showed satisfactory outcomes, which enhanced osseointegration, biomechanics, and histology [77-79], which is a promising therapeutic strategy for ACLR.

\subsection{Differentiation Induction}

3.2.1. Biologic Factors. It is a consensus that growth factors could regulate cell proliferation, ECM elaboration, neovascularization, and mechanical properties. Hence, knowing the exact signaling mechanisms involved in ligament development and repair are essential for improving ACL regeneration, but our current knowledge is much limited and further research needs to be done. Functionally, it has been empirically shown that various growth factors exert positive effects on ligament tissues. Such as transforming growth factor (TGF), fibroblast growth factor (FGF), insulin-like growth factor (IGF), platelet-derived growth factor (PDGF), and epidermal growth factor (EGF), with all having been proven to increase cell proliferation, fibroblastic differentiation, and ECM deposition. As a combination of these factors, PRP could induce mass release of growth factors within one hour following intra-articular administration, which seems a convenient and efficient tool, but related meta-analysis studies found no significant benefit for ACLR in the clinic [80, 81].

Teng et al. found that PRP promoted BMSC osteodifferentiation in vitro. Moreover, PRP+BMSCs yielded better tendon-bone healing in rabbits [82]. Single growth factor, such as VEGF [83], also achieved good outcomes. To maintain the effects of these cytokines, gene therapy is a good solution. Runx2 gene upregulated the expression of osteogenic markers and enhanced tendon-bone healing with more new bone tissue formation, without heterotopic ossification [84]. The same results were achieved with BMP2, bFGF, TGF, VEGF, and PDGF gene transfection. Cotransfection of multiple genes is more powerful and efficient for osteogenic differentiation rather than either single gene therapy in Chen et al.'s study [85].

3.2.2. Mechanics. Mechanical loading has been demonstrated to influence cell proliferation, differentiation, apoptosis, and ECM production without growth factors [86-88]. In fibroblasts, mechanical stimulus has been shown to increase cell proliferation, and ECM deposition [89]. It improves tendon-bone healing after ACLR by increasing the amount of fibrocartilage and mechanics. In vitro, BMSC/TC coculture stimulated by mechanical stretch showed higher expression levels of collagen I/III, alkaline phosphatase, osteopontin, and tenascin C [90], as well as BMSC alone [88]. In fact, the time, direction, magnitude, and frequency of mechanical stimulation would all influence the cell condition. Early mechanical loading on MSCs inhibited the expression of collagen type I, collagen type II, and fibronectin but enhanced these during the proliferation stage [91]. $8 \%$ but not $4 \%$ cyclical strain on ligament fibroblasts resulted in better proliferation and collagen production [92]. But it is difficult to control these mechanical parameters in vivo, so we need further investigations of the cultured environment before implantation. These could explain how prolonged immobilization would result in the mechanics of damage within the clinic [93].

3.2.3. Biomaterials. In tissue engineering, cell differentiation can be induced by growing the cells on scaffolds with specific composition, architecture, and physicochemical and mechanical properties. Biomaterials not only play a load-bearing role in ACL reconstruction but is also a differentiation inducer.

In native ACL, type I collagen constitutes roughly $90 \%$ of the tissue volume, so the use of collagen-based scaffolds has been extensively investigated. Collagen could promote tenogenic differentiation induction, and the collagen-induced tenogenic cells could then arrest osteogenic differentiation mediated by paracrine signals [94]. But immunogenicity and low mechanical strength often limit the application of collagen-based scaffolds. Similar to collagen, silk is a natural biologic material with good tensile strength and biodegradation, but its limited cell adhesion requires some special modification, such as with arginine-glycine-aspartic acid. Silk scaffolds have also been shown to support BMSC attachment and proliferation within a three-dimensional environment and can induce synthesis of fibroblastic markers upon the application of dynamic mechanical loading [95]. Moreover, the hydrophilic properties of silk also influence the proliferation of seeded cells [96]. Electrospinning is a popular and simple technique for fabricating scaffolds with fiber diameters in the nanometer to micron range. Studies showed good capacity of polymer material-based electrospun fibers in promoting tendon fibroblast and MSC proliferation, as well as ECM deposition [97, 98]. Various mechanical parameters of different materials may affect the differentiation of stem cells, such as elastic modulus [99, 100], hydrophilicity or hydrophobicity [101], and substrate topography [102]. Stem cells seeded on aligned nanofibers displayed a more elongated shape with more Scx and ECM marker expression than randomly oriented nanofibers [102, 103]. Graphenequantum dots could promote MSC osteogenic and adipogenic differentiation [104].

So far, silk scaffold, electrospun scaffold, and decellularized allograft with BMSCs have demonstrated good osseointegration capacity [105-107]. To simulate the insertion stratified structure better, a triphasic silk-based graft was established with BMSCs, chondrocytes, and osteoblasts seeded on different areas of the graft [42]. More novel materials combined with biologics are gaining in popularity.

3.3. Cell Fate. The fate of implanted stem cells remains controversial. Ju et al. used the fluorescent marker Dil dye to track implanted sMSCs, which initially stayed at the tendon-bone interface, and then differentiated into fibroblasts, with the potential of producing collagen fibers or secreting various cytokines for collagen fiber synthesis. But DiI-labeled cells could no longer be observed after 4 weeks [108]. There are three plausible reasons to explain this: missing label, cell replacement, or apoptosis. Lui et al. used the grafts wrapped with the GFP-TDSC sheet for ACLR, but only 
few GFP+ cells could be detected at the tunnel interface and the intra-articular graft midsubstance, with the cell number reducing with time [59]. Takeuchi et al. used engineered $\mathrm{Tg}$ pigs to track how endogenous cells infiltrate into the graft [12]. The graft was first surrounded by synovia-like tissue with fluorescence at first, then a large number of metabolically active oval cells infiltrated the peripheral region of the graft, resulting in a shift to an equal distribution of oval and spindle-shaped cells. Eventually, spindle-shaped fibroblastlike cells were uniformly distributed, resembling the natural ACL histology.

In some ACL injury models, exogenous cells were detected in the synovium, injured ACL, meniscus, cartilage of femoral condyles, and myotendinous junction of the quadriceps $[109,110]$. Transplanted MSCs may produce growth factors such as PDGF, bFGF, and TGF- $\beta$, which promote native ACL cell proliferation and migration [111]. Maerz et al. found that tail-injected circulating MSCs preferentially migrate to the synovium of the injured joint, with the upregulation of SDF-1 (chemokines) in the synovial fluid. However, MSC did not enter the intra-articular tissues [110].

The objective of these studies was to form a normal insertion structure, but the source of newly formed fibrocartilage cells remains a mystery. Due to differentiation of the original cells, whether these are derived from transplanted exogenous stem cells or recruited endogenous cells remains ambiguous. How do these MSCs differentiate into fibroblast or other lineages? Tracking of cell fate needs to be more rigorously investigated.

\section{Clinical Applications}

The search in electronic databases such as PubMed, Embase, and Cochrane Library resulted in 9 clinical trials (Figure 3), including 5 ongoing trials and 4 completed trials [112-115] (trial details see Appendix), highlighting the ongoing evolution of this field.

Based on the published results of completed clinical trials, the overall outcome was quite disappointing (Table 3). Wang et al. showed that the injection of allogeneic BMSCs after ACL reconstruction is safe and tolerable, improving the symptoms and delaying the progress of $\mathrm{OA}$ [112]. However, Silva et al. found no significant acceleration in tendon-bone healing with MRI [114]. Alentorn-Geli et al. utilized ADSCs in 20 soccer players with ACL reconstruction and found no statistically significant difference compared to ACLR alone, with respect to pain, biomechanical functions, and MRI scores [115]. Park et al. [116] conducted a 2-year follow-up with patients with hUCB-MSC augmentation and found no statistical differences in biomechanical functions, arthroscopic findings, or tunnel enlargement. Additionally, a noncontrolled trial utilizing autologous bone marrow aspirate combined with PRP and platelet lysate found safe outcomes with MRI and evaluation of clinical function [113].

\section{Prospects}

5.1. Cell Transplantation. Though preclinical studies have shown promising outcomes, the general clinical effects of stem cells on ACL graft regeneration are controversial, and the heterogeneity of transplanted stem cells needs to be further investigated with more high-quality research studies needed for an accurate and comprehensive conclusion. The clinical application of stem cells is a complex process, in view of the host tissue environment, time, cell adhesion, and dose. Due to the poor blood supply and insufficient nutrition provided by the articular cavity, too much cell injection will lead to necrosis, while too little will not yield a satisfactory effect. Dose- and time-dependent clinical research studies need to be carried out.

The timing of injecting or transplanting stem cells requires further consideration. Based on the process of graft regeneration as described above, two different therapeutic strategies for utilizing stem cells in ACL regeneration have been proposed: (a) during the early stage, transplanted stem cells make up for the hypocellularity, and the immunoregulatory property of MSCs (especially BMSCs) reduces inflammation reaction, as well as facilitate recruitment/activation of endogenous stem cells. Macrophages would accumulate for repair at the tendon-bone interface but often result in the formation of a scar tissue rather than normal insertion site [117], and so the regulation of macrophages by stem cells can enhance tendon-bone healing; (b) the application of stem cells during the remodeling stage may avoid apoptosis of transplanted cells due to poor blood supply. After angiogenesis and ECM deposition, the inner environment may be more suitable for stem cells to implant during the noninflammatory stage [118], but formed ECM may block the implanted cells to migrate towards the inner tendon. Additionally, abundant growth factors such as bFGF, TGF- $\beta 1$, and PDGF [22] have demonstrated potent effects on tenogenic differentiation induction [119-121].

Different delivery methods have their own pros and cons. To attract stem cells into the scaffold, chemokines can be applied [65]. To simulate the insertion stratified structure, a triphasic silk-based graft was established with different cell types [42, 122], with specific induction treatment being applied to different parts of the graft. Decellularized allogenic scaffold is more similar to the original environment and enables easy seeding of cells [107]. To solve the problem of biocompatibility, biodegradability, and immunogenicity, cell sheet is a new option, which can be harvested from temperature-responsive culture dishes, and it has indeed shown promising outcomes in animal studies $[59,66]$. In the clinic, due to the limitations of biomaterial approval, most trials deliver stem cell via injection, which often results in substantial loss of MSCs. Grafts wrapped in stem cell collagen seem a safe and simple solution. In summary, a carrier with great natural biodegradability, cell adhesion, biomechanics, biocompatibility, and insertion spatial simulation is required, and silk-based scaffolds have shown promising potential.

5.2. Differentiation of Stem Cells into Tendon/Ligament Cell Lineages. In embryos, tendon development requires both physiological and biomechanical stimulation [123, 124]. Temporal coordination of various physiological signals at early developmental stages, such as TGF- $\beta$, BMP, and FGF 


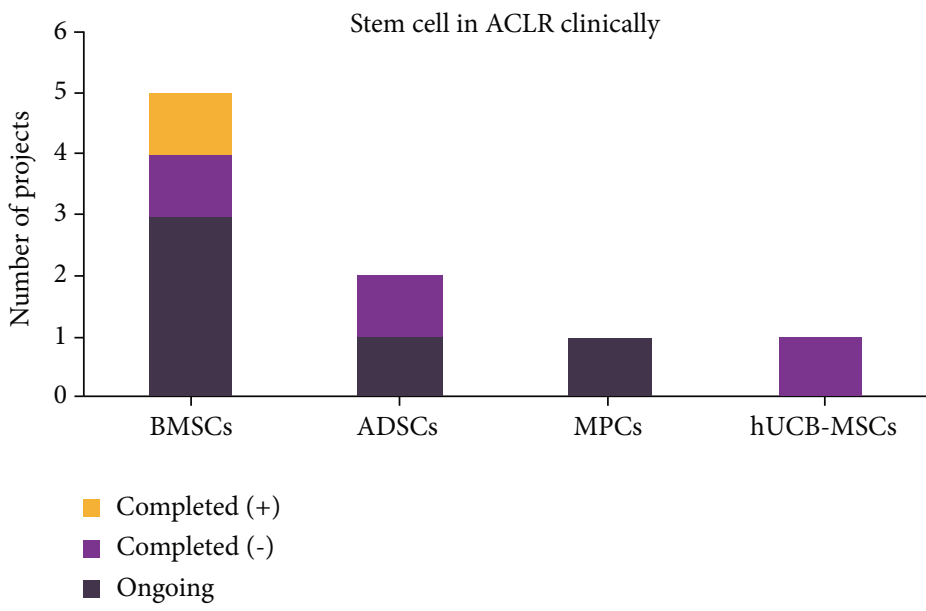

FIGURE 3: The number of ongoing and completed clinical projects with positive or negative results in the application of different stem cell lineages after ACL reconstruction. BMSC: bone marrow-derived mesenchymal stem cells; MPC: mesenchymal precursor cell; ADSC: adipose tissue-derived stem cell; hCDB-MSC: human cord blood-derived mesenchymal stem cell.

TABLe 3: Published clinical trials of stem cell therapy for ACL graft regeneration.

\begin{tabular}{|c|c|c|c|c|c|c|}
\hline Author & $\begin{array}{l}\text { Cell } \\
\text { resource }\end{array}$ & Patient* & Follow-up & Evaluation & Outcome & Other outcomes \\
\hline Wang et al. [112] & BMSCs & 11 vs. 6 & $2 y$ & $\begin{array}{l}\text { Adverse event; pain; } \\
\text { function; MRI; LifeQ }\end{array}$ & + & $\begin{array}{c}\text { Less pain, symptoms, bone expansion, joint space } \\
\text { narrowing, and cartilage volume loss }\end{array}$ \\
\hline Silva et al. [149] & BMSCs & 20 vs. 23 & $1 \mathrm{y}$ & MRI & - & No signal-to-noise ratio difference \\
\hline $\begin{array}{l}\text { Alentorn-Geli } \\
\text { et al. [115] }\end{array}$ & ADSCs & 20 vs. 19 & $1 \mathrm{y}$ & Pain; function; MRI & - & \\
\hline Park et al. [116] & $\begin{array}{l}\text { hUCB- } \\
\text { MSCs }\end{array}$ & $\begin{array}{l}10 \text { vs. } 10 \\
\text { vs. } 10^{\#}\end{array}$ & $2 y$ & $\begin{array}{l}\text { Adverse event; KT; } \\
\text { function; arthroscopy }\end{array}$ & - & Safe but no clinical advantage \\
\hline
\end{tabular}

${ }^{*}$ The experimental group (ACLR+stem cell) vs. the negative control group (ACLR); ${ }^{*}$ the experimental group (ACLR+stem cell+HA) vs. the negative control group (ACLR) vs. the positive control group (ACLR+HA).

[125-127], as well as biomechanical stimulation at later stage [123], promotes tenogenic differentiation. The origin of ACL is still under research. Most joint tissues derive from GDF5(+) mesenchymal cell [128], of which Lgr5 $+/ \mathrm{Scx}+/ \mathrm{Col} 22 \mathrm{a} 1-$ interzone cells are restricted within the ligament lineage [129]. Scx+/Sox9+ precursors are also considered as the origin of the ACL [130], although exact signaling mechanisms involved in ligament development are still unclear. Several markers of embryonic tendon development were identified, but these do not provide functional properties. Based on embryonic tendon development, step induction is a logical method for simulating the development of tenocytes, with enhanced self-renewal, and long-term viability. Chen et al. induced hESCs to differentiate into MSCs and subsequently allow the MSCs to form tendon-like tissues with mechanical stress in vitro and in vivo [131].

Learning from embryonic tendon development can improve tendon tissue engineering strategies with adult stem cells, and tenogenic cues and markers will need to be established for step-wise induction [132]. Some studies have delivered MSCs together with exogenous proteinogenic growth factors to induce tenogenic differentiation. TGF is considered as an inducer of the tendon transcription factor Scx [70, 127], which can direct MSC differentiation towards the tenogenic lineage [119]. FGF mainly promotes matrix production for tendon maturation [120], and FGF4 treatment has been shown to significantly downregulate the gene expression levels of all tendon markers (Scx, TGF $\beta 2$, Tnmd, Col I, and elastin) in MSCs but can only downregulate the mRNA levels of elastin in TDSC [121]. The BMP family of growth factors is essential to both osteogenic and chondrogenic differentiation [126], which may activate cytoskeletal reorganization or the Smad signaling pathway $[133,134]$. In particular, BMP-12/13/14 signaling has been shown to be proteinogenic [135]. CTGF also plays an auxiliary role during tenogenic differentiation, by activating Scx, Tnmd, and other ECM marker expression, inducing fibroblastic effect and ECM production $[136,137]$. In addition, Wnt signal was found to induce Tnmd expression in BMSCs via glycogen synthase kinase-3 [138]. These signaling factors play key roles in tendon differentiation and regeneration.

All stem cell therapies have the inherent risk of tumorigenicity, due to the aberration of chromosomal, copy number, and single nucleotide, hindering clinical translation [139, 140]. Hence, some researchers have turned to exosomes as an alternative, the specific vesicles secreted by stem cells, which can directly deliver the bioactive factors with low risk 
of tumorigenicity and undesired spontaneous differentiation. A similar tool is conditioned medium (CM), which represents a mixture of different factors secreted by the cells. The application of BMSC-CM accelerates graft-bone incorporation and midsubstance ligamentization and enhances differentiation as well [141]. These cell-free preparations have the advantages of less ossification, less calcification, and easy restoration, with various different proteins, nucleic acids, and lipid components being linked to their potency.

5.3. Current Challenges in Stem Cell Therapy for ACLR. Although challenges exist, preclinical evidence predicts a promising future for stem cell approach to ACLR, despite most (3/4) clinical research studies showing controversial outcomes. Currently, there are several ongoing human clinical trials in this area. Due to few studies on stem cell therapy for ACLR, we are unable to conduct a deep meta-analysis in this systematic review. In general, how exactly stem cells participate in human ACL regeneration and whether it has clinical benefits will require further study.

In addition, because stem cell transplantation is a biological therapeutic strategy, the stability and oncogenicity of stem cells require consistent long-term safety verification. The published scientific literature confirms the short-term ( $<24$ months) safety and tolerance of stem cells in ACLR, but the implanted cells need long-term tracking, which has been poorly studied to date.

Third, the choice of the stem cell source is another important consideration. Stem cells derived from different sources all showed good capacity in promoting regeneration, but their relative effects need to be compared to optimize the therapeutic efficacy. With respect to availability and ease of isolation, ADSCs and BMSCs may have advantages over other stem cell types. In terms of proliferative capacity and ligamentous differentiation potential, TDSC/LDSC is regarded as having the most potential, but limited cell quantity may limit clinical applications. Proper differentiation of alternative stem cell lineages either in vitro or in vivo will be particularly crucial, because they are capable of differentiating into multiple tissue types. Current applications in humans are at the primary stage, so the differentiation induction in vivo is not mature and safe. Moreover, the implantation methodology and cell fate have been discussed previously, including the dose, time, supplementary agent, and material.

\section{Conclusion}

Almost all utilized stem cell lineages showed good capacity in promoting tendon-bone regeneration in animal models. Among the various different stem cell types, BMSCs are most commonly investigated, while LDSC/TDCS showed better potential for tendon/ligament lineage-specific differentiation. With differentiation inducers, such as growth factors, mechanical stimuli, and biomaterials, stem cells have better capacity to differentiate into ligament, fibrocartilage, and bone, as well as regulate inflammation through paracrine pathways, promoting graft regeneration. The application of stem cells in the clinic often results in disappointing outcomes and needs further investigations.

\section{Conflicts of Interest}

The authors declare that they have no conflicts of interest.

\section{Supplementary Materials}

The detail of clinical trials in the application of different stem cell lineages after ACL reconstruction. Description: a comprehensive search of the literature was carried out in Sep. 2nd, 2020, using electronic databases PubMed, Embase, and Cochrane Library. The keywords "anterior cruciate ligament" and "stem cell" were combined without language or time restrictions. The results were limited to RCTs. (Supplementary Materials)

\section{References}

[1] M. A. Risberg, M. Lewek, and L. Snyder-Mackler, "A systematic review of evidence for anterior cruciate ligament rehabilitation: how much and what type?," Physical Therapy in Sport, vol. 5, no. 3, pp. 125-145, 2004.

[2] J. L. Carey and K. G. Shea, "AAOS clinical practice guideline," The Journal of the American Academy of Orthopaedic Surgeons, vol. 23, no. 5, pp. e6-e8, 2015.

[3] S. Bollen, "Epidemiology of knee injuries: diagnosis and triage," British Journal of Sports Medicine, vol. 34, no. 3, pp. 227-228, 2000.

[4] S. E. Florida, K. W. VanDusen, V. D. Mahalingam et al., "In vivo structural and cellular remodeling of engineered boneligament-bone constructs used for anterior cruciate ligament reconstruction in sheep," Connective Tissue Research, vol. 57, no. 6, pp. 526-538, 2016.

[5] D. J. Biau, C. Tournoux, S. Katsahian, P. Schranz, and R. Nizard, "ACL reconstruction: a meta-analysis of functional scores," Clinical Orthopaedics and Related Research, vol. 458, pp. 180-187, 2007.

[6] A. Gobbi, M. Domzalski, J. Pascual, and M. Zanazzo, "Hamstring anterior cruciate ligament reconstruction: is it necessary to sacrifice the gracilis?," Arthroscopy, vol. 21, no. 3, pp. 275-280, 2005.

[7] M. I. Pitman, N. Nainzadeh, D. Menche, R. Gasalberti, and S. Eun Kyoo, "The intraoperative evaluation of the neurosensory function of the anterior cruciate ligament in humans using somatosensory evoked potentials," Arthroscopy, vol. 8, no. 4, pp. 442-447, 1992.

[8] M. Sánchez, E. Anitua, J. Azofra, R. Prado, F. Muruzabal, and I. Andia, "Ligamentization of tendon grafts treated with an endogenous preparation rich in growth factors: gross morphology and histology," Arthroscopy, vol. 26, no. 4, pp. 470-480, 2010.

[9] W. A. Grana, D. M. Egle, R. Mahnken, and C. W. Goodhart, "An analysis of autograft fixation after anterior cruciate ligament reconstruction in a rabbit model," The American Journal of Sports Medicine, vol. 22, no. 3, pp. 344-351, 1994.

[10] H. H. Lu and S. Thomopoulos, "Functional attachment of soft tissues to bone: development, healing, and tissue engineering," Annual Review of Biomedical Engineering, vol. 15, pp. 201-226, 2013.

[11] S. Kawamura, L. Ying, H. J. Kim, C. Dynybil, and S. A. Rodeo, "Macrophages accumulate in the early phase of tendon-bone 
healing," Journal of Orthopaedic Research, vol. 23, no. 6, pp. 1425-1432, 2005.

[12] H. Takeuchi, Y. Niki, H. Matsunari et al., "Temporal changes in cellular repopulation and collagen fibril remodeling and regeneration after allograft anterior cruciate ligament reconstruction: an experimental study using Kusabira-Orange transgenic pigs," The American Journal of Sports Medicine, vol. 44, no. 9, pp. 2375-2383, 2016.

[13] V. K. Goradia, M. C. Rochat, W. A. Grana, M. D. Rohrer, and H. S. Prasad, "Tendon-to-bone healing of a semitendinosus tendon autograft used for ACL reconstruction in a sheep model," The American Journal of Knee Surgery, vol. 13, no. 3, pp. 143-151, 2000.

[14] P. A. Zuk, M. Zhu, P. Ashjian et al., "Human adipose tissue is a source of multipotent stem cells," Molecular Biology of the Cell, vol. 13, no. 12, pp. 4279-4295, 2002.

[15] A. I. Caplan, "Adult mesenchymal stem cells for tissue engineering versus regenerative medicine," Journal of Cellular Physiology, vol. 213, no. 2, pp. 341-347, 2007.

[16] A. I. Caplan and J. E. Dennis, "Mesenchymal stem cells as trophic mediators," Journal of Cellular Biochemistry, vol. 98, no. 5, pp. 1076-1084, 2006.

[17] V. B. Duthon, C. Barea, S. Abrassart, J. H. Fasel, D. Fritschy, and J. Ménétrey, "Anatomy of the anterior cruciate ligament," Knee Surgery, Sports Traumatology, Arthroscopy, vol. 14, no. 3, pp. 204-213, 2006.

[18] M. Marieswaran, I. Jain, B. Garg, V. Sharma, and D. Kalyanasundaram, "A review on biomechanics of anterior cruciate ligament and materials for reconstruction," Applied Bionics and Biomechanics, vol. 2018, Article ID 4657824, 14 pages, 2018.

[19] R. P. Janssen and S. U. Scheffler, "Intra-articular remodelling of hamstring tendon grafts after anterior cruciate ligament reconstruction," Knee Surgery, Sports Traumatology, Arthroscopy, vol. 22, no. 9, pp. 2102-2108, 2014.

[20] S. Abe, M. Kurosaka, T. Iguchi, S. Yoshiya, and K. Hirohata, "Light and electron microscopic study of remodeling and maturation process in autogenous graft for anterior cruciate ligament reconstruction," Arthroscopy, vol. 9, no. 4, pp. 394-405, 1993.

[21] J. B. Kleiner, D. Amiel, R. D. Roux, and W. H. Akeson, "Origin of replacement cells for the anterior cruciate ligament autograft," Journal of Orthopaedic Research, vol. 4, no. 4, pp. 466-474, 1986.

[22] R. Kuroda, M. Kurosaka, S. Yoshiya, and K. Mizuno, "Localization of growth factors in the reconstructed anterior cruciate ligament: immunohistological study in dogs," Knee Surgery, Sports Traumatology, Arthroscopy, vol. 8, no. 2, pp. 120-126, 2000.

[23] S. U. Scheffler, F. N. Unterhauser, and A. Weiler, "Graft remodeling and ligamentization after cruciate ligament reconstruction," Knee Surgery, Sports Traumatology, Arthroscopy, vol. 16, no. 9, pp. 834-842, 2008.

[24] A. Weiler, G. Peters, J. Mäurer, F. N. Unterhauser, and N. P. Südkamp, "Biomechanical properties and vascularity of an anterior cruciate ligament graft can be predicted by contrast-enhanced magnetic resonance imaging. A two-year study in sheep," The American Journal of Sports Medicine, vol. 29, no. 6, pp. 751-761, 2001.

[25] S. Liu, Y. Sun, F. Wan, Z. Ding, S. Chen, and J. Chen, “Advantages of an attached semitendinosus tendon graft in anterior cruciate ligament reconstruction in a rabbit model," The American Journal of Sports Medicine, vol. 46, no. 13, pp. 3227-3236, 2018.

[26] S. Liu, H. Li, H. Tao, Y. Sun, S. Chen, and J. Chen, "A randomized clinical trial to evaluate attached hamstring anterior cruciate ligament graft maturity with magnetic resonance imaging," The American Journal of Sports Medicine, vol. 46, no. 5, pp. 1143-1149, 2018.

[27] T. Yoshikawa, H. Tohyama, T. Katsura et al., "Effects of local administration of vascular endothelial growth factor on mechanical characteristics of the semitendinosus tendon graft after anterior cruciate ligament reconstruction in sheep," The American Journal of Sports Medicine, vol. 34, no. 12, pp. 1918-1925, 2006.

[28] J. R. Jackson, J. A. Minton, M. L. Ho, N. Wei, and J. D. Winkler, "Expression of vascular endothelial growth factor in synovial fibroblasts is induced by hypoxia and interleukin lbeta," The Journal of Rheumatology, vol. 24, no. 7, pp. 1253-1259, 1997.

[29] K. Shino, T. Kawasaki, H. Hirose, I. Gotoh, M. Inoue, and K. Ono, "Replacement of the anterior cruciate ligament by an allogeneic tendon graft. An experimental study in the dog," Journal of Bone and Joint Surgery. British Volume (London), vol. 66, no. 5, pp. 672-681, 1984.

[30] H. Lu, C. Chen, S. Xie, Y. Tang, and J. Qu, “Tendon healing in bone tunnel after human anterior cruciate ligament reconstruction: a systematic review of histological results," The Journal of Knee Surgery, vol. 32, no. 5, pp. 454-462, 2019.

[31] W. Petersen, F. Unterhauser, T. Pufe, T. Zantop, N. P. Südkamp, and A. Weiler, "The angiogenic peptide vascular endothelial growth factor (VEGF) is expressed during the remodeling of free tendon grafts in sheep," Archives of Orthopaedic and Trauma Surgery, vol. 123, no. 4, pp. 168-174, 2003.

[32] F. N. Unterhauser, H. J. Bail, J.??. H??her, N. P. Haas, and A. Weiler, "Endoligamentous revascularization of an anterior cruciate ligament graft," Clinical Orthopaedics and Related Research, vol. 414, pp. 276-288, 2003.

[33] M. Åhlén, L. Roshani, M. Lidén, A. Struglics, L. RostgårdChristensen, and J. Kartus, "Inflammatory cytokines and biomarkers of cartilage metabolism 8 years after anterior cruciate ligament reconstruction: results from operated and contralateral knees," The American Journal of Sports Medicine, vol. 43, no. 6, pp. 1460-1466, 2015.

[34] K. Marumo, M. Saito, T. Yamagishi, and K. Fujii, "The "ligamentization" process in human anterior cruciate ligament reconstruction with autogenous patellar and hamstring tendons: a biochemical study," The American Journal of Sports Medicine, vol. 33, no. 8, pp. 1166-1173, 2005.

[35] H. Sofu, Y. Camurcu, A. Issin, H. Ucpunar, S. Ozcan, and S. Duman, "Should orthopedic surgeons consider reducing the negative effects of Outerbridge grade 2 patellofemoral chondral lesion on early postoperative recovery during anterior cruciate ligament reconstruction," European Journal of Orthopaedic Surgery \& Traumatology: Orthopedie Traumatologie, vol. 29, no. 2, pp. 471-478, 2019.

[36] M. Vogrin, M. Rupreht, A. Crnjac, D. Dinevski, Z. Krajnc, and G. Rečnik, "The effect of platelet-derived growth factors on knee stability after anterior cruciate ligament reconstruction: a prospective randomized clinical study," Wiener Klinische Wochenschrift, vol. 122, Supplement. 2, pp. 9195, 2010. 
[37] A. V. Azcárate, J. Lamo-Espinosa, J. D. A. Beola, M. H. Gonzalez, G. M. Gasque, and J. R. V. Nin, "Comparison between two different platelet-rich plasma preparations and control applied during anterior cruciate ligament reconstruction. Is there any evidence to support their use?," Injury, vol. 45, Supplement 4, pp. S36-S41, 2014.

[38] A. Agarwalla, R. N. Puzzitiello, J. N. Liu et al., "Timeline for maximal subjective outcome improvement after anterior cruciate ligament reconstruction," The American Journal of Sports Medicine, vol. 47, no. 10, pp. 2501-2509, 2019.

[39] P. Rama, S. Matuska, G. Paganoni, A. Spinelli, M. de Luca, and G. Pellegrini, "Limbal stem-cell therapy and long-term corneal regeneration," The New England Journal of Medicine, vol. 363, no. 2, pp. 147-155, 2010.

[40] A. Trounson and C. McDonald, "Stem cell therapies in clinical trials: progress and challenges," Cell Stem Cell, vol. 17, no. 1, pp. 11-22, 2015.

[41] Y. Mifune, T. Matsumoto, S. Ota et al., "Therapeutic potential of anterior cruciate ligament-derived stem cells for anterior cruciate ligament reconstruction," Cell Transplantation, vol. 21, no. 8, pp. 1651-1665, 2012.

[42] H. G. Li, J. Fan, L. Sun, X. Liu, P. Cheng, and H. Fan, "Functional regeneration of ligament-bone interface using a triphasic silk- based graft," Biomaterials, vol. 106, pp. 180-192, 2016.

[43] M. Kosaka, J. Nakase, K. Hayashi, and H. Tsuchiya, “Adipose-derived regenerative cells promote tendon-bone healing in a rabbit model," Arthroscopy, vol. 32, no. 5, pp. 851-859, 2016.

[44] Y. Sakaguchi, I. Sekiya, K. Yagishita, and T. Muneta, "Comparison of human stem cells derived from various mesenchymal tissues - superiority of synovium as a cell source," Arthritis and Rheumatism, vol. 52, no. 8, pp. 2521-2529, 2005.

[45] A. Uccelli, L. Moretta, and V. Pistoia, "Mesenchymal stem cells in health and disease," Nature Reviews. Immunology, vol. 8, no. 9, pp. 726-736, 2008.

[46] J. Lim, J. Hui, L. Li, A. Thambyah, J. Goh, and E. Lee, "Enhancement of tendon graft osteointegration using mesenchymal stem cells in a rabbit model of anterior cruciate ligament reconstruction," Arthroscopy, vol. 20, no. 9, pp. 899-910, 2004.

[47] C. I. Hur, H. W. Ahn, J. K. Seon, E. K. Song, and G. E. Kim, "Mesenchymal stem cells decrease tunnel widening of anterior cruciate ligament reconstruction in rabbit model," International Journal of Stem Cells, vol. 12, no. 1, pp. 162-169, 2019.

[48] Y. Zhang, D. Khan, J. Delling, and E. Tobiasch, "Mechanisms underlying the osteo- and adipo-differentiation of human mesenchymal stem cells," Scientific World Journal, vol. 2012, article 793823, 14 pages, 2012.

[49] L. Otero-Ortega, M. Gutiérrez-Fernández, J. Ramos-Cejudo et al., "White matter injury restoration after stem cell administration in subcortical ischemic stroke," Stem Cell Research \& Therapy, vol. 6, no. 1, p. 121, 2015.

[50] A. C. Uysal and H. Mizuno, "Tendon regeneration and repair with adipose derived stem cells," Current Stem Cell Research \& Therapy, vol. 5, no. 2, pp. 161-167, 2010.

[51] T. Schubert, D. Xhema, S. Vériter et al., "The enhanced performance of bone allografts using osteogenic-differentiated adipose-derived mesenchymal stem cells," Biomaterials, vol. 32, no. 34, pp. 8880-8891, 2011.

[52] A. Lafosse, C. Desmet, N. Aouassar et al., "Autologous adipose stromal cells seeded onto a human collagen matrix for dermal regeneration in chronic wounds: clinical proof of concept," Plastic and Reconstructive Surgery, vol. 136, no. 2, pp. 279-295, 2015.

[53] M. J. Eagan, P. A. Zuk, K. W. Zhao et al., "The suitability of human adipose-derived stem cells for the engineering of ligament tissue," Journal of Tissue Engineering and Regenerative Medicine, vol. 6, no. 9, pp. 702-709, 2012.

[54] A. H. Teuschl, S. Tangl, P. Heimel et al., "Osteointegration of a novel silk fiber-based ACL scaffold by formation of a ligament-bone interface," The American Journal of Sports Medicine, vol. 47, no. 3, pp. 620-627, 2019.

[55] K. Kim, R. Zhao, A. Doi et al., "Donor cell type can influence the epigenome and differentiation potential of human induced pluripotent stem cells," Nature Biotechnology, vol. 29, no. 12, pp. 1117-1119, 2011.

[56] Y. Bi, D. Ehirchiou, T. M. Kilts et al., "Identification of tendon stem/progenitor cells and the role of the extracellular matrix in their niche," Nature Medicine, vol. 13, no. 10, pp. 12191227, 2007.

[57] D. Stanco, M. Viganò, C. P. Orfei et al., "In vitro characterization of stem/progenitor cells from semitendinosus and gracilis tendons as a possible new tool for cell-based therapy for tendon disorders," Joints, vol. 2, no. 4, pp. 159-168, 2014.

[58] Q. Tan, P. P. Y. Lui, Y. F. Rui, and Y. M. Wong, "Comparison of potentials of stem cells isolated from tendon and bone marrow for musculoskeletal tissue engineering," Tissue Engineering. Part A, vol. 18, no. 7-8, pp. 840-851, 2012.

[59] P. P. Lui, O. T. Wong, and Y. W. Lee, “Application of tendonderived stem cell sheet for the promotion of graft healing in anterior cruciate ligament reconstruction," The American Journal of Sports Medicine, vol. 42, no. 3, pp. 681-689, 2014.

[60] D. Stanco, M. Viganò, C. Perucca Orfei et al., "Multidifferentiation potential of human mesenchymal stem cells from adipose tissue and hamstring tendons for musculoskeletal cellbased therapy," Regenerative Medicine, vol. 10, no. 6, pp. 729-743, 2015.

[61] C. A. Ghebes, C. Kelder, T. Schot et al., "Anterior cruciate ligament- and hamstring tendon-derived cells: in vitro differential properties of cells involved in ACL reconstruction," Journal of Tissue Engineering and Regenerative Medicine, vol. 11, no. 4, pp. 1077-1088, 2017.

[62] B. Chen, J. Zhang, D. Nie, G. Zhao, F. H. Fu, and J. H.-. C. Wang, "Characterization of the structure of rabbit anterior cruciate ligament and its stem/progenitor cells," Journal of Cellular Biochemistry, vol. 120, pp. 7446-7457, 2019.

[63] Y. Ogata, Y. Mabuchi, K. Shinoda et al., “Anterior cruciate ligament-derived mesenchymal stromal cells have a propensity to differentiate into the ligament lineage," Regenerative Therapy, vol. 8, pp. 20-28, 2018.

[64] Z. Hao, H. Wu, Y. Li, S. Wang, and J. Lu, "Comparison of biological characteristics between bone marrow mesenchymal stem cells and anterior cruciate ligament derived mesenchymal stem cells in rats," Zhongguo Xiu Fu Chong Jian Wai Ke Za Zhi, vol. 31, no. 4, pp. 473-480, 2017.

[65] Y. Hu, J. Ran, Z. Zheng et al., "Exogenous stromal derived factor-1 releasing silk scaffold combined with intra- 
articular injection of progenitor cells promotes boneligament-bone regeneration," Acta Biomaterialia, vol. 71, pp. 168-183, 2018.

[66] Y. Mifune, T. Matsumoto, K. Takayama et al., “Tendon graft revitalization using adult anterior cruciate ligament (ACL)-derived CD34+ cell sheets for ACL reconstruction," Biomaterials, vol. 34, no. 22, pp. 5476-5487, 2013.

[67] T. Matsumoto, S. M. Ingham, Y. Mifune et al., "Isolation and characterization of human anterior cruciate ligament-derived vascular stem cells," Stem Cells and Development, vol. 21, no. 6, pp. 859-872, 2012.

[68] S. Woods, N. Bates, S. L. Dunn, F. Serracino-Inglott, T. E. Hardingham, and S. J. Kimber, "Generation of humaninduced pluripotent stem cells from anterior cruciate ligament," Journal of Orthopaedic Research, vol. 38, no. 1, pp. 92-104, 2020.

[69] S. H. Park, Y. J. Choi, S. W. Moon et al., “Three-dimensional bio-printed scaffold sleeves with mesenchymal stem cells for enhancement of tendon-to-bone healing in anterior cruciate ligament reconstruction using soft-tissue tendon graft," Arthroscopy, vol. 34, no. 1, pp. 166-179, 2018.

[70] K. M. Jang, H. C. Lim, W. Y. Jung, S. W. Moon, and J. H. Wang, "Efficacy and safety of human umbilical cord bloodderived mesenchymal stem cells in anterior cruciate ligament reconstruction of a rabbit model: new strategy to enhance tendon graft healing," Arthroscopy, vol. 31, no. 8, pp. 15301539, 2015.

[71] J. B. Yang, X. Z. Zhu, H. Z. Xiong, Y. W. Li, Y. Jin, and Y. Liu, "Biocompatibility of human amniotic mesenchymal stem cells with human acellular amniotic membrane scaffold," Chinese Journal of Tissue Engineering Research, vol. 22, no. 5, pp. 742-747, 2018.

[72] T. Morito, T. Muneta, K. Hara et al., "Synovial fluid-derived mesenchymal stem cells increase after intra-articular ligament injury in humans," Rheumatology, vol. 47, no. 8, pp. 1137-1143, 2008.

[73] C. Takenaka, N. Nishishita, N. Takada, L. M. Jakt, and S. Kawamata, "Effective generation of iPS cells from CD $34^{+}$ cord blood cells by inhibition of p53," Experimental Hematology, vol. 38, no. 2, pp. 154-162.e2, 2010.

[74] Y. H. Loh, S. Agarwal, I. H. Park et al., "Generation of induced pluripotent stem cells from human blood," Blood, vol. 113, no. 22, pp. 5476-5479, 2009.

[75] S. Wakitani, K. Takaoka, T. Hattori et al., "Embryonic stem cells injected into the mouse knee joint form teratomas and subsequently destroy the joint," Rheumatology, vol. 42, no. 1, pp. 162-165, 2003.

[76] D. Kouroupis, A. Kyrkou, E. Triantafyllidi et al., "Generation of stem cell-based bioartificial anterior cruciate ligament (ACL) grafts for effective ACL rupture repair," Stem Cell Research, vol. 17, no. 2, pp. 448-457, 2016.

[77] H. Shen, S. Yoneda, Y. Abu-Amer, F. Guilak, and R. H. Gelberman, "Stem cell-derived extracellular vesicles attenuate the early inflammatory response after tendon injury and repair," Journal of Orthopaedic Research, vol. 38, pp. 117$127,2019$.

[78] Y. J. Wang, G. He, Y. Guo et al., "Exosomes from tendon stem cells promote injury tendon healing through balancing synthesis and degradation of the tendon extracellular matrix," Journal of Cellular and Molecular Medicine, vol. 23, no. 8, pp. 5475-5485, 2019.
[79] C. S. Chamberlain, A. E. B. Clements, J. A. Kink et al., "Extracellular vesicle-educated macrophages promote early Achilles tendon healing," Stem Cells, vol. 37, no. 5, pp. 652-662, 2019.

[80] M. S. Davey, E. T. Hurley, D. Withers, R. Moran, and C. J. Moran, "Anterior cruciate ligament reconstruction with platelet-rich plasma: a systematic review of randomized control trials," Arthroscopy-the Journal of Arthroscopic and Related Surgery, vol. 36, no. 4, pp. 1204-1210, 2020.

[81] E. Trams, K. Kulinski, K. Kozar-Kaminska, S. Pomianowski, and R. Kaminski, "The clinical use of platelet-rich plasma in knee disorders and surgery-a systematic review and metaanalysis," Life, vol. 10, no. 6, 2020.

[82] C. Teng, C. Zhou, D. Xu, and F. Bi, "Combination of plateletrich plasma and bone marrow mesenchymal stem cells enhances tendon-bone healing in a rabbit model of anterior cruciate ligament reconstruction," Journal of Orthopaedic Surgery and Research, vol. 11, no. 1, p. 96, 2016.

[83] R. Setiawati, D. N. Utomo, F. A. Rantam, N. N. Ifran, and N. C. Budhiparama, "Early graft tunnel healing after anterior cruciate ligament reconstruction with intratunnel injection of bone marrow mesenchymal stem cells and vascular endothelial growth factor," Orthopaedic Journal of Sports Medicine, vol. 5, no. 6, p. $232596711770854,2017$.

[84] X. Zhang, Y. Ma, X. Fu et al., "Runx2-Modified AdiposeDerived Stem Cells Promote Tendon Graft Integration in Anterior Cruciate Ligament Reconstruction," Scientific Reports, vol. 6, no. 1, pp. 19073-19073, 2016.

[85] B. Chen, B. Li, Y. J. Qi et al., "Enhancement of tendon-tobone healing after anterior cruciate ligament reconstruction using bone marrow-derived mesenchymal stem cells genetically modified with bFGF/BMP2," Scientific Reports, vol. 6, no. 1, p. 25940, 2016.

[86] J. C. Chen and C. R. Jacobs, "Mechanically induced osteogenic lineage commitment of stem cells," Stem Cell Research \& Therapy, vol. 4, no. 5, p. 107, 2013.

[87] D. J. Kelly and C. R. Jacobs, "The role of mechanical signals in regulating chondrogenesis and osteogenesis of mesenchymal stem cells," Birth Defects Research. Part C, Embryo Today, vol. 90, no. 1, pp. 75-85, 2010.

[88] G. H. Altman, H. H. Lu, R. L. Horan et al., "Advanced bioreactor with controlled application of multi-dimensional strain for tissue engineering," Journal of Biomechanical Engineering, vol. 124, no. 6, pp. 742-749, 2002.

[89] C. C. Berry, J. C. Shelton, D. L. Bader, and D. A. Lee, "Influence of external uniaxial cyclic strain on oriented fibroblastseeded collagen gels," Tissue Engineering, vol. 9, no. 4, pp. 613-624, 2003.

[90] F. Song, D. Jiang, T. Wang et al., "Mechanical loading improves tendon-bone healing in a rabbit anterior cruciate ligament reconstruction model by promoting proliferation and matrix formation of mesenchymal stem cells and tendon cells," Cellular Physiology and Biochemistry, vol. 41, no. 3, pp. 875-889, 2017.

[91] J. E. Moreau, D. S. Bramono, R. L. Horan, D. L. Kaplan, and G. H. Altman, "Sequential biochemical and mechanical stimulation in the development of tissue-engineered ligaments," Tissue Engineering. Part A, vol. 14, no. 7, pp. 1161-1172, 2008.

[92] S. A. Park, I. A. Kim, Y. J. Lee et al., "Biological responses of ligament fibroblasts and gene expression profiling on micropatterned silicone substrates subjected to mechanical 
stimuli," Journal of Bioscience and Bioengineering, vol. 102, no. 5, pp. 402-412, 2006.

[93] S. L. Woo, M. A. Gomez, T. J. Sites, P. O. Newton, C. A. Orlando, and W. H. Akeson, "The biomechanical and morphological changes in the medial collateral ligament of the rabbit after immobilization and remobilization," The Journal of Bone and Joint Surgery. American Volume, vol. 69, no. 8, pp. 1200-1211, 1987.

[94] J. X. Lin, W. Zhou, S. Han et al., "Cell-material interactions in tendon tissue engineering," Acta Biomaterialia, vol. 70, pp. 111, 2018.

[95] J. Chen, G. H. Altman, V. Karageorgiou et al., "Human bone marrow stromal cell and ligament fibroblast responses on RGD-modified silk fibers," Journal of Biomedical Materials Research. Part A, vol. 67, no. 2, pp. 559-570, 2003.

[96] A. R. Murphy, P. S. John, and D. L. Kaplan, "Modification of silk fibroin using diazonium coupling chemistry and the effects on hMSC proliferation and differentiation," Biomaterials, vol. 29, no. 19, pp. 2829-2838, 2008.

[97] R. James, U. S. Toti, C. T. Laurencin, and S. G. Kumbar, "Electrospun nanofibrous scaffolds for engineering soft connective tissues," Methods in Molecular Biology, vol. 726, pp. 243-258, 2011.

[98] R. D. Cardwell, L. A. Dahlgren, and A. S. Goldstein, "Electrospun fibre diameter, not alignment, affects mesenchymal stem cell differentiation into the tendon/ligament lineage," Journal of Tissue Engineering and Regenerative Medicine, vol. 8, no. 12, pp. 937-945, 2014.

[99] A. J. Engler, M. A. Griffin, S. Sen, C. G. Bönnemann, H. L. Sweeney, and D. E. Discher, "Myotubes differentiate optimally on substrates with tissue-like stiffness: pathological implications for soft or stiff microenvironments," Journal of Cell Biology, vol. 166, no. 6, pp. 877-887, 2004.

[100] A. M. Handorf, Y. Zhou, M. A. Halanski, and W. J. Li, "Tissue stiffness dictates development, homeostasis, and disease progression," Organogenesis, vol. 11, no. 1, pp. 115, 2015.

[101] B. G. Keselowsky, D. M. Collard, and A. J. Garcia, "Integrin binding specificity regulates biomaterial surface chemistry effects on cell differentiation," Proceedings of the National Academy of Sciences of the United States of America, vol. 102, no. 17, pp. 5953-5957, 2005.

[102] Z. Yin, X. Chen, J. L. Chen et al., "The regulation of tendon stem cell differentiation by the alignment of nanofibers," Biomaterials, vol. 31, no. 8, pp. 2163-2175, 2010.

[103] C. Zhang, H. Yuan, H. Liu et al., "Well-aligned chitosanbased ultrafine fibers committed teno-lineage differentiation of human induced pluripotent stem cells for Achilles tendon regeneration," Biomaterials, vol. 53, pp. 716-730, 2015.

[104] J. Qiu, D. Li, X. Mou et al., "Effects of graphene quantum dots on the self-renewal and differentiation of mesenchymal stem cells," Advanced Healthcare Materials, vol. 5, no. 6, pp. 702710, 2016.

[105] H. Fan, H. Liu, E. J. W. Wong, S. L. Toh, and J. C. H. Goh, "In vivo study of anterior cruciate ligament regeneration using mesenchymal stem cells and silk scaffold," Biomaterials, vol. 29, no. 23, pp. 3324-3337, 2008.

[106] J. X. Zhu, X. Zhang, Z. Shao et al., "In vivo study of ligamentbone healing after anterior cruciate ligament reconstruction using autologous tendons with mesenchymal stem cells affinity peptide conjugated electrospun nanofibrous scaffold,"
Journal of Nanomaterials, vol. 2013, Article ID 831873, 11 pages, 2013.

[107] W. Lu, J. Xu, S. Dong et al., “Anterior cruciate ligament reconstruction in a rabbit model using a decellularized allogenic semitendinous tendon combined with autologous bone marrow-derived mesenchymal stem cells," Stem Cells Translational Medicine, vol. 8, no. 9, pp. 971-982, 2019.

[108] Y. J. Ju, T. Muneta, H. Yoshimura, H. Koga, and I. Sekiya, "Synovial mesenchymal stem cells accelerate early remodeling of tendon-bone healing," Cell and Tissue Research, vol. 332, no. 3, pp. 469-478, 2008.

[109] M. Agung, M. Ochi, S. Yanada et al., "Mobilization of bone marrow-derived mesenchymal stem cells into the injured tissues after intraarticular injection and their contribution to tissue regeneration," Knee Surgery, Sports Traumatology, Arthroscopy, vol. 14, no. 12, pp. 1307-1314, 2006.

[110] T. Maerz, M. Fleischer, M. D. Newton et al., "Acute mobilization and migration of bone marrow-derived stem cells following anterior cruciate ligament rupture," Osteoarthritis and cartilage, vol. 25, no. 8, pp. 1335-1344, 2017.

[111] A. Kanaya, M. Deie, N. Adachi, M. Nishimori, S. Yanada, and M. Ochi, "Intra-articular injection of mesenchymal stromal cells in partially torn anterior cruciate ligaments in a rat model," Arthroscopy, vol. 23, no. 6, pp. 610-617, 2007.

[112] Y. Wang, A. Shimmin, P. Ghosh et al., "Safety, tolerability, clinical, and joint structural outcomes of a single intraarticular injection of allogeneic mesenchymal precursor cells in patients following anterior cruciate ligament reconstruction: a controlled double-blind randomised trial," Arthritis Research \& Therapy, vol. 19, no. 1, pp. 180-180, 2017.

[113] C. Centeno, J. Markle, E. Dodson et al., "Symptomatic anterior cruciate ligament tears treated with percutaneous injection of autologous bone marrow concentrate and platelet products: a non-controlled registry study," Journal of Translational Medicine, vol. 16, no. 1, p. 246, 2018.

[114] A. Silva, R. Sampaio, R. Fernandes, and E. Pinto, "Is there a role for adult non-cultivated bone marrow stem cells in ACL reconstruction?," Knee Surgery, Sports Traumatology, Arthroscopy: Official Journal of the ESSKA, vol. 22, no. 1, pp. 66-71, 2014.

[115] E. Alentorn-Geli, R. Seijas, A. Martínez-de la Torre et al., "Effects of autologous adipose-derived regenerative stem cells administered at the time of anterior cruciate ligament reconstruction on knee function and graft healing," Journal of Orthopaedic Surgery, vol. 27, no. 3, p. 230949901986758, 2019.

[116] S. W. M. J. H. W. S. H. Park, “A randomized clinical trial for safety and efficacy of human umbilical cord blood derived mesenchymal stem cells to enhance tendon graft healing in anterior cruciate ligament reconstruction with two years follow up," 2019, https://www.cochranelibrary.com/central/doi/ 10.1002/central/CN-01994267/full\#abstract.

[117] P. L. Hays, S. Kawamura, X. H. Deng et al., "The role of macrophages in early healing of a tendon graft in a bone tunnel," The Journal of Bone and Joint Surgery. American Volume, vol. 90, no. 3, pp. 565-579, 2008.

[118] S. Sözkesen, H. G. Karahan, A. Kurtulmus, C. Kayali, and T. Altay, "PRP on prevention of tunnel enlargement in ACL reconstruction," Ortopedia, Traumatologia, Rehabilitacja, vol. 20, no. 4, pp. 285-291, 2018. 
[119] E. Havis, M.-A. Bonnin, I. Olivera-Martinez et al., "Transcriptomic analysis of mouse limb tendon cells during development," Development, vol. 141, no. 19, pp. 36833696, 2014.

[120] J. B. Tang, Y. F. Wu, Y. Cao et al., "Basic FGF or VEGF gene therapy corrects insufficiency in the intrinsic healing capacity of tendons," Scientific Reports, vol. 6, 2016.

[121] J. P. Brown, V. G. Finley, and C. K. Kuo, "Embryonic mechanical and soluble cues regulate tendon progenitor cell gene expression as a function of developmental stage and anatomical origin," Journal of Biomechanics, vol. 47, no. 1, pp. 214-222, 2014.

[122] J. Fan, L. Sun, X. Chen et al., "Implementation of a stratified approach and gene immobilization to enhance the osseointegration of a silk-based ligament graft," Journal of Materials Chemistry B, vol. 5, no. 34, pp. 7035-7050, 2017.

[123] C. K. Kuo and R. S. Tuan, "Mechanoactive tenogenic differentiation of human mesenchymal stem cells," Tissue Engineering. Part A, vol. 14, no. 10, pp. 1615-1627, 2008.

[124] G. Nourissat, F. Berenbaum, and D. Duprez, “Tendon injury: from biology to tendon repair," Nature Reviews Rheumatology, vol. 11, no. 4, pp. 223-233, 2015.

[125] A. E. Brent and C. J. Tabin, "FGF acts directly on the somitic tendon progenitors through the Ets transcription factors Pea 3 and Erm to regulate scleraxis expression," Development, vol. 131, no. 16, pp. 3885-3896, 2004.

[126] P. H. Francis-West, J. Parish, K. Lee, and C. W. Archer, "BMP/GDF-signalling interactions during synovial joint development," Cell and Tissue Research, vol. 296, no. 1, pp. 111-119, 1999.

[127] B. A. Pryce, S. S. Watson, N. D. Murchison, J. A. Staverosky, N. Dünker, and R. Schweitzer, "Recruitment and maintenance of tendon progenitors by TGFbeta signaling are essential for tendon formation," Development, vol. 136, no. 8, pp. 1351-1361, 2009.

[128] E. Koyama, Y. Shibukawa, M. Nagayama et al., "A distinct cohort of progenitor cells participates in synovial joint and articular cartilage formation during mouse limb skeletogenesis," Developmental Biology, vol. 316, no. 1, pp. 62-73, 2008.

[129] C. Feng, W. C. W. Chan, Y. Lam et al., "Lgr 5 and Col 22a1 mark progenitor cells in the lineage toward juvenile articular chondrocytes," Stem Cell Reports, vol. 13, no. 4, pp. 713-729, 2019.

[130] T. Soeda, J. M. Deng, B. de Crombrugghe, R. R. Behringer, T. Nakamura, and H. Akiyama, "Sox9-expressing precursors are the cellular origin of the cruciate ligament of the knee joint and the limb tendons," Genesis, vol. 48, no. 11, pp. 635-644, 2010.

[131] X. Chen, X. H. Song, Z. Yin et al., "Stepwise differentiation of human embryonic stem cells promotes tendon regeneration by secreting fetal tendon matrix and differentiation factors," Stem Cells, vol. 27, no. 6, pp. 1276-1287, 2009.

[132] T. Nakajima and M. Ikeya, "Development of pluripotent stem cell-based human tenocytes," Development, Growth \& Differentiation, vol. 63, pp. 38-46, 2020.

[133] S. L. Tan, T. S. Ahmad, W. M. Ng et al., "Identification of pathways mediating growth differentiation Factor5-Induced tenogenic differentiation in human bone marrow stromal cells," PLoS One, vol. 10, no. 11, article e0140869, 2015.

[134] H. Shen, R. H. Gelberman, M. J. Silva, S. E. Sakiyama-Elbert, and S. Thomopoulos, "BMP12 induces tenogenic differentia- tion of adipose-derived stromal cells," PLoS One, vol. 8, no. 10, article e77613, 2013.

[135] P. Eliasson, A. Fahlgren, and P. Aspenberg, "Mechanical load and BMP signaling during tendon repair: a role for follistatin?," Clinical Orthopaedics and Related Research, vol. 466, no. 7, pp. 1592-1597, 2008.

[136] J. Liu, X. Tao, L. Chen, W. Han, Y. Zhou, and K. Tang, "CTGF positively regulates BMP12 induced tenogenic differentiation of tendon stem cells and signaling," Cellular Physiology and Biochemistry, vol. 35, no. 5, pp. 1831-1845, 2015.

[137] Z. Yin, J. Guo, T. Y. Wu et al., "Stepwise differentiation of mesenchymal stem cells augments tendon-like tissue formation and defect repair in vivo," Stem Cells Translational Medicine, vol. 5, no. 8, pp. 1106-1116, 2016.

[138] S. Miyabara, Y. Yuda, Y. Kasashima, A. Kuwano, and K. Arai, "Regulation of tenomodulin expression via $\mathrm{Wnt} / \beta$-catenin signaling in equine bone marrow-derived mesenchymal stem cells," Journal of Equine Science, vol. 25, no. 1, pp. 7-13, 2014.

[139] K. Takayama, Y. Kawakami, Y. Mifune et al., "The effect of blocking angiogenesis on anterior cruciate ligament healing following stem cell transplantation," Biomaterials, vol. 60, pp. 9-19, 2015.

[140] M. Yoshihara, Y. Hayashizaki, and Y. Murakawa, "Genomic instability of iPSCs: challenges towards their clinical applications," Stem Cell Reviews and Reports, vol. 13, no. 1, pp. 7-16, 2017.

[141] Y. Sun, W. Chen, Y. Hao et al., "Stem cell-conditioned medium promotes graft remodeling of midsubstance and intratunnel incorporation after anterior cruciate ligament reconstruction in a rat model," The American Journal of Sports Medicine, vol. 47, no. 10, pp. 2327-2337, 2019.

[142] S. Kern, H. Eichler, J. Stoeve, H. Klüter, and K. Bieback, "Comparative analysis of mesenchymal stem cells from bone marrow, umbilical cord blood, or adipose tissue," Stem Cells, vol. 24, no. 5, pp. 1294-1301, 2006.

[143] J. K. Fraser, I. Wulur, Z. Alfonso, and M. H. Hedrick, "Fat tissue: an underappreciated source of stem cells for biotechnology," Trends in Biotechnology, vol. 24, no. 4, pp. 150-154, 2006.

[144] Y. Bi, T. Kilts, C. Inkson, S. Shi, and M. F. Young, "Identification of tendon stem cells and the implications for understanding ectopic ossification," Journal of Bone and Mineral Research, vol. 21, article S133-S, p. , 2006.

[145] P. Prager, M. Schieker, F. Jakob, D. Docheva, C. Konrads, and A. Steinert, "Characterization of human telomerase reverse transcriptase immortalized anterior cruciate ligament cell lines," Biomedical Journal, vol. 42, no. 6, pp. 371-380, 2019.

[146] T. Vazin and W. J. Freed, "Human embryonic stem cells: derivation, culture, and differentiation: a review," Restorative Neurology and Neuroscience, vol. 28, no. 4, pp. 589-603, 2010.

[147] J. W. Riggs, B. L. Barrilleaux, N. Varlakhanova, K. M. Bush, V. Chan, and P. S. Knoepfler, "Induced pluripotency and oncogenic transformation are related processes," Stem Cells and Development, vol. 22, no. 1, pp. 37-50, 2013.

[148] T. B. Zhao, Z. N. Zhang, Z. Rong, and Y. Xu, "Immunogenicity of induced pluripotent stem cells," Nature, vol. 474, no. 7350, pp. 212-215, 2011.

[149] A. Silva, R. Sampaio, R. Fernandes, and E. Pinto, "Is there a role for adult non-cultivated bone marrow stem cells in ACL reconstruction? Knee surgery, sports traumatology," Knee Surgery, Sports Traumatology, Arthroscopy, vol. 22, no. 1, pp. 66-71, 2014. 